NBER WORKING PAPER SERIES

\title{
ADJUSTING THE GROSS CHANGES DATA: \\ IMPLICATIONS FOR \\ LABOR MARKET DYNAMICS
}

\author{
James M. Poterba \\ Lawrence $\mathrm{H}$. Surmers
}

Working Paper No. 1436

\author{
NATIONAL BUREAU OF ECONOMIC RESEARCH \\ 1050 Massachusetts Avenue \\ Cambridge, MA 02138 \\ August 1984
}

\begin{abstract}
A preliminary version was prepared for the BLS/Census Conference on Gross Changes Data, July 19 and July 20, 1984. After completing most of the research reported here we learned of related work being conducted by Wayne Fuller and Tin Chiu Chua (1984) and John Abowd and Amold Zellner (1984). We are indebted to Bruce Meyer for excellent research assistance, to Irv Scheiner for assistance with the data, and to Wayne Fuller and Francis Horvath for helpful discussions. We thank the NBER and NSF for financial support. The research reported here is part of the NBER's research program in Labor Studies. Any opinions expressed are those of the authors and not those of the National Bureau of Economic Research.
\end{abstract}


NBER Working Paper \#1436 August 1984

\author{
Adjusting the Gross Changes Data: \\ Implications for Labor Market Dynamics
}

\title{
ABSTRACT
}

This paper develops a procedure for adjusting the Current Population Survey gross changes data for the effects of reporting errors. The corrected data suggest that the labor market is much less dynamic than has frequently been suggested. Conventional measures may understate the duration of unemployment by as mach as eighty percent and overstate the extent of movement into and out of the labor force by several hundred percent. The adjusted data also throw demographic differences in patterns of labor market dynamics into sharp relief.

James M. Poterba

Department of Economics

Massachusetts Institute

of Technology and NBER

Cambridge, MA 02139

(617) 253-6673
Lawrence H. Summers Department of Economics Harvard University and NBER Cambridge, MA 02138 (617) 495-2447 
The dynamics of the American labor market have been an important focus of research over the last decade. Early work by Hall [12], Feldstein [8] and Marston [16] suggested that most unemployment was due to normal turnover, not to individuals with special employment problems. A typical conclusion was that of Feldstein who wrote that "almost everyone who is out of work can find his usual job in a relatively short time." This dynamic view of unemployment has been challenged in the more recent work of Clark and Summers [6] and Akerlof and Main [2]. Clark and Summers in particular focus on how analysts can be misled by spurious labor market transitions, writing that "it seems likely that some of the observed flows [into and out of the labor force] arise from inconsistent reporting of consistent behavior [7, p. 28]." This paper re-examines the empirical basis of these debates.

Studies of labor market dynamics are of necessity based on survey data. In some cases inferences are drawn from individual responses to retrospective questions. In other cases, presumably more accurate inferences are drawn from panel data in which individuals are interviewed several times. The BLS Gross Changes data, which have been tabulated since 1948, are a major source of such information about individuals: labor market experience. While the data have not been published in recent years due to concerns about accuracy; they have been used in mumerous studies of labor market dynamics.l

The report of the National Commission on Employment and Unemployment Statistics [17] recommended that despite the data difficulties, the BLS should resume publication of the gross flows data on an occasional basis. The Commission concluded that "the importance of Current Population Surveybased gross changes data for enhancing understanding of changes in the labor market requires that very high priority be given to improvement in the data. 
... It is possible, of course, that a solution will not be achieved, but the potential value of the data warrants an intensive effort $[17$, p. 217]."

In using longitudinal data, the flows of individuals between different labor market states are derived by comparing the responses of individuals on two different survey dates. On each survey, some individuals are incorrectly classified with respect to labor market status. While these errors may largely cancel in tabulations of the unemployment rate or other labor market aggregates, estimated flow rates between labor market states are extremely sensitive to them. Individuals who are misclassified in one month but not in the next will be reported as moving from one state to another even though their behavior has not changed. Some observed transitions will therefore be spurious, leading to overestimates of the amount of turnover and mobility in the labor market. Such errors can substantially bias estimates of the expected duration of both unemployment and nonparticipation spells. They are also likely to bias inferences about subtler aspects of labor market dynamics, such as efforts to estimate "state dependence" effects.

This paper presents a technique for correcting the classification errors which plague the Current Population Survey (CPS) gross flows data. Similar techniques could readily be applied to other data sets. We use the CPS Reinterview Survey to estimate the incidence of errors in the gross changes data, and then calculate revised flows by adjusting for spurious transitions. The results of our procedure suggest that conventional measures greatly overstate flows into and out of the labor force. As a consequence, standard estimates of unemployment durations, whether based directly on gross 
flows data or on other information such as the average duration of completed or incomplete spells, are biased downwards. The labor force attachment of some groups, notably women and teenagers, has also been significantly underestimated.

This paper is divided into four sections. The first explains our procedure for estimating the incidence of response errors which affect the CPS and therefore the gross changes data. Section Two presents our algorithm for adjusting the gross changes data, and contrasts our revised labor market flows with the unadjusted data. The third section uses the adjusted flows to analyze several characteristics of the American labor market, focussing on differences in the experience of different demographic groups. There is a brief concluding section which suggests several directions for future work. 
1. The Incidence of Classification Errors in the Current Population Survey

We need to calculate a matrix of response error rates showing the probability that an individual whose true labor market status is $i\left(S_{T}=i\right)$ will be classified as into state $f$ on his first CPS interview $\left(s_{1}=j\right)$. We define $q_{i j}=$ $\operatorname{Pr}\left(S_{1}=j \mid S_{T}=i\right)$. Labor market status has three possible values: $E$ (employed), $U$ (unemployed), and $N$ (not in the labor force). The matrix of error rates is therefore

$$
Q=\left[\begin{array}{lll}
q_{E E} & q_{E U} & q_{E N} \\
q_{U E} & q_{U U} & q_{U N} \\
q_{N E} & q_{N U} & q_{N N}
\end{array}\right]
$$

where, for example, $\mathrm{q}_{\mathrm{EN}}$ is the probability that an individual who is employed will be measured as not-in-the-labor force. There are only six independent probabilities in this matrix, since the elements of each row sum to unity.

The principal source of data on the incidence of errors in the Current Population Survey is the Reinterview Survey conducted by the Bureau of the Census.2 This survey measures coding error and evaluates interviewer performance by reinterviewing a subsample of CPS households. In the initial interview, respondents are asked about their activities in the previous week. Reinterviews occur one week after the initial interview, and involve 5.6 percent of the respondents in the original survey. During the reinterview, respondents are asked to describe their activities two weeks prior to the reinterview, in the week referred to in the initial interview.

Individuals in the reinterview survey are divided into a Reconciled and an 
Unreconciled Subsample. For the 80 percent of the reinterviews in the Reconciled Subsample, the reinterviewer conducts a second interview and then compares the results with those on the first survey. He then attempts to determine which, if either, of any conflicting responses is correct. The results of this reconciliation are recorded on a third form and tabulated along with the survey responses. For the twenty percent of the Reinterview Survey respondents in the Unreconciled Subsample, there is no attempt to investigate differences between responses on the first and second surveys. The reinterviewer conducts a second interview without reference to responses on the first interview. The Bureau of the Census publishes tabulations of Reinterview Survey results for some highly aggregated demographic groups. To investigate differences in labor market experience for different demographic groups, we made our own tabulations of error rates from Reinterview Survey data tapes provided by the Bureau of the Census. Our data set contains 25,314 reinterviews conducted between January and June, 1981.

Table I shows the distribution of recorded labor market status for individuals in the Reconciled and Unreconciled Subsamples of the Reinterview Survey for the period January-June, 1981. The table shows the percentage of individuals in each Reinterview subsample by their classified labor market status on each survey. Off-diagonal elements correspond to different responses on the two surveys. The table suggests a significant amount of response error in the CPS. More than five percent of individuals in the Unreconciled Subsample were classified differently on the two surveys.

There are several ways to use the reinterview survey data to estimate 
Table I: Survey Response Inconsistencies, CPS Reinterview Survey

Reconciled Subsample: Initial Interview vs. Reinterview

\begin{tabular}{l} 
Initial \\
Interview \\
Status \\
\hline
\end{tabular}

Employed

Unemployed

NILF

\begin{tabular}{|c|c|c|}
\hline Imployed & Unemployed & NILF \\
\hline $57.69 *$ & 0.17 & 0.71 \\
\hline 0.18 & 4.02 & 0.34 \\
\hline 0.90 & 0.66 & 35.34 \\
\hline
\end{tabular}

Reconciled Subsample: Initial Interview vs. Reconciliation

Initial

Interview

Status

Employed

Unemployed

NILF

\section{Reconciliation Status}

Employed

. 58.32

Unemployed

$\underline{\text { NILF }}$

0.19

0.11

0.06

0.10

0.63

4.33

0.46

35.81

Unreconciled Subsample: Initial Interview vs. Reinterview

Initial

Interview

Status

Employed

Unemployed

NILF

$$
\text { Reinterview Status }
$$

Employed

Unemployed

NILF

57.65

0.59

1.53

0.43

3.28

0.71

1.35

0.82

33.64

Each entry represents the percentage of individuals recorded in a particular pair of labor market states, i.e., 57.69 percent of the individuals in the Reconciled Subsample were recorded as employed in the interview and reinterview. Calculations are based on authors' tabulations based on Current Population Survey Reinterview Survey data for the period January-June, 1981, provided by the Bureau of the Census. See text for further details. 
the incidence of survey response errors.3 All are plagued by the fact that the true labor market status of survey participants is never revealed. Data on some individual's reconciled data entries may even be subject to errors, especially since consistent but incorrect responses on the initial interview and the reinterview will not prompt any investigation by the reinterviewer.

A simple procedure for estimating error rates would involve comparing individuals' responses on the first survey with their recorded response after reconciliation. Estimates of the response error rates based only on the Reconciled Subsample of the Reinterview Survey are commonly regarded as downward-biased, however. 4 This is in part because some reinterviewers, who are provided with a copy of the household's original survey responses, may use the original survey answers as a guide in completing the reinterview survey. This minimizes the need for reconciliation and yields an overlyreliable picture of the Current Population Survey. The rate of inconsistencies between the first and second interviews is substantially higher in the Unreconciled Subsample than in the Reconciled Subsample.

A more accurate estimate of the response error rates, and therefore of the adjusted gross changes, can be obtained using data from both the Reconciled and the Unreconciled Subsamples. Our procedure may be described in two parts. First, for individuals in the Reconciled Subsample, we estimated the probability of truly belonging to each labor market state conditional upon reported first and second interview status $\left(\mathrm{S}_{1}\right.$ and $\left.\mathrm{S}_{2}\right)$. These probabilities are:

$$
w_{i j k}=\operatorname{Pr}\left(s_{T}=k \mid s_{1}=i, s_{2}=j\right)
$$

To estimate these probabilities, we assumed that when there were inconsistencies 
between the two survey responses, the reconciliation procedure correctly identified true labor market status. Our estimator was therefore:

$$
\hat{w}_{i j k}=\operatorname{Pr}\left(s_{R}=k \mid s_{1}=i, s_{2}=j\right) \text {. }
$$

There are twenty-seven such probabilities, but since they must satisfy adding up conditions of the form

$$
w_{i j E}+w_{1 j U}+w_{i j N}=1
$$

for each i-j combination, only eighteen parameters are independent.

We assume that the Reconciled Subsample contains a partial sample of the cases for which Initial Interview and Reinterview responses were different. Reinterviewers in some cases consult the household's responses on the initial survey before conducting the reinterview. Some inconsistent responses are thereby avoided, explaining the lower rate of inconsistent response for the Reconciled as opposed to the Unreconciled Subsample. Although the Reconciled Subsample provides a misleading estimate of the incidence of response errors, it may nonetheless provide reliable estimates of the fraction of inconsistent cases which should be allocated to each of the two recorded responses.

We used the estimates $\left\{\hat{w}_{i j k}\right\}$ to impute the probability distribution of true labor market status for each individual in the Unreconciled Subsample, conditional upon his responses as recorded in the initial interview and the Reinterview. The number of individuals in the Unreconciled Subsample with each true labor market status was estimated as

$$
\begin{aligned}
\mathrm{N}_{\mathrm{k}} & =\begin{array}{l}
\text { Number of individuals in the unreconciled } \\
\text { subsample with imputed labor market status } \mathrm{k}
\end{array}
\end{aligned}
$$




$$
=\sum_{i} \sum_{j} \hat{w}_{i j k} N_{i j}^{U}
$$

where $\mathrm{N}_{i j} \mathrm{U}$ is the number of individuals in the Unreconciled Subsample for whom the first interview status is $i$, and the second interview status is $\mathrm{g}$. From these estimates we estimated the probability than an individual observed in a particular labor market state on either the first or second survey was actually in state $k$. The probability that our synthetic reconciliation status equals a particular value, conditional upon the individual's recorded first survey response, is

(5a)

$$
\hat{q}_{x y}=\frac{\sum_{j} \hat{w}_{x j y} \cdot N_{x j}^{U}}{\sum_{j} N_{x j}^{U}}=\operatorname{Pr}\left(\hat{s}_{T}=y \mid S_{1}=x\right)
$$

where $\hat{S}_{T}$ denotes the imputed value of labor market status. An identical procedure could be performed using the reinterview survey data as the observed response, yielding:

$$
\hat{q}_{x y}=\frac{\sum_{i} \hat{w}_{i x y} \cdot N_{i x}^{U}}{\sum_{i} N_{i x}^{U}}=\operatorname{Pr}\left(\hat{s}_{T}=y \mid s_{2}=x\right) .
$$

We formed the estimated error rates which are used in our subsequent analysis by averaging $\hat{q}_{x y}$ and $\hat{q}_{x y}$ ":

(5c) $\quad \hat{q}_{x y}^{*}=\left(\hat{q}_{x y}^{\prime}+\hat{q}_{x y}^{\prime \prime}\right) / 2$.

Since $\stackrel{q}{q}_{x y} \cong q_{x y}^{\prime \prime} \cong q_{x y}^{*}$, the choice amongst the three estimators was of little significance. 
The resulting estimates of classification error probabilities are shown in Table II. The table displays separate error rates for men, women, the entire population, as well as seven other demographic groups. Only the off-diagonal elements of the $Q$ matrix are shown, since the other terms can be computed from them. The highest error rates are found for individuals whose reconciled status is unemployed. In the whole survey, over eleven percent of the unemployed are incorrectly classified as not in the labor force. The fraction of unemployed persons misclassified in this way varies across demographic groups, from less than seven percent for middle-aged men (aged 25-59) to over seventeen percent for young women (aged 16-19). For teenagers of both sexes, the error rate is nearly fourteen percent; at all ages, the error rate is substantially higher for women than for men.

The second most important type of misclassification is from unemployment into employment. Almost four percent of the unemployed individuals in the population are incorrectly classified as holding a job; this error rate rises to over six percent for male teenagers. Errors in which employed individuals are classified as not-in-the-labor force are also surprisingly frequent: neariy two percent of the employed, and three and a half percent of teenagers, are miscategorized in this way. Most other error rates are small for the total population, although for some demographic groups they may become significant. For example, among men aged 25-59 who are out of the labor force, there is a substantial probability ( 3.8 percent) that they will be misclassified as employed. The demographic variation in error rates highlights the importance of disaggregating the flows before making adjustments for classification errors. 
Table II: Estimated Response Errors in the Current Population Survey

\begin{tabular}{|c|c|c|c|c|c|c|}
\hline \multirow{2}{*}{$\begin{array}{l}\text { Demographic } \\
\text { Group }\end{array}$} & \multirow[b]{2}{*}{$\mathrm{q}_{\mathrm{EU}}$} & \multirow[b]{2}{*}{$\mathrm{q}_{\mathrm{EN}}$} & \multicolumn{2}{|c|}{ Error Rate } & \multirow[b]{2}{*}{${ }^{q_{N E}}$} & \multirow[b]{2}{*}{$\mathrm{q}_{\mathrm{NU}}$} \\
\hline & & & $q_{U E}$ & $q_{U N}$ & & \\
\hline Total & .0054 & .0172 & .0378 & .1146 & .0116 & .0064 \\
\hline Total $16-19$ & .0126 & .0361 & .0472 & .1393 & .0131 & .0126 \\
\hline Men & .0065 & .0119 & .0435 & .0895 & .0165 & .0105 \\
\hline Men 16-19 & .0168 & .0350 & .0644 & .1134 & .0120 & .0143 \\
\hline Men $20-24$ & .0137 & .0077 & .0550 & .0728 & .0170 & .0378 \\
\hline Men $25-59$ & .0046 & .0062 & .0316 & .0700 & .0378 & .0332 \\
\hline Women & .0041 & .0237 & .0321 & .1470 & .0096 & .0050 \\
\hline Women $16-19$ & .0088 & .0380 & .0222 & .1736 & .0130 & .0114 \\
\hline Women $20-24$ & .0096 & .0218 & .0234 & .1011 & .0239 & .0105 \\
\hline Women 25-59 & .0029 & .0168 & .0380 & .1688 & .0106 & .0062 \\
\hline
\end{tabular}

Notes: Error rates calculated by the authors from data on Reinterview Surveys between January and June 1981. See text for further description of the calculations. 
Before turning to the next section where we describe how these error probabilities are used to adjust the gross changes data, it is important to mention several potential biases in our estimated $\left\{\hat{q}_{1 j}\right\}$. Reinterviewers are instructed to try to interview the same person who was interviewed in the original survey. No similar practice is followed in successive months of the regular CPS survey, probably leading to higher response error rates than those reported here. In addition, if the reconciliation procedure fails to identify an individual's true labor market status, our estimates of response error will be too small. There are also biases which work in the opposite direction. The Reinterview Survey may exaggerate the extent of error since a week is allowed to pass between the events being described and the survey week. The Reinterview Survey is frequently conducted by phone which may tend to exaggerate response errors. Finally, although different CPS interviewers contact different numbers of households, the Reinterview Survey typically contacts a fixed number of households for each interviewer. If there is any relationship between the efficiency of interviewers (measured by the number of interviews they conduct) and their accuracy, then there will be additional biases in our estimates of response error. 


\section{Adjusting the Gross Changes Data}

In this section we describe our procedure for using the estimated $\left\{\hat{q}_{i j}\right\}$ to adjust the reported gross changes. Let $F_{i j}$ denote the measured flow. from labor market state $i$ to state $j$, while $F_{i j}^{*}$ is the true flow. The notation $\hat{F}_{i j}$ will refer to our estimates of the true flows. We can use the $\left\{\hat{q}_{i j}\right\}$ to relate the "true" and measured flows. For example, consider the measured flow from employment to unemployment. There are nine different combinations of actual labor market statuses and response errors which can lead an individual CPS respondent to be classified as making an $E+U$ transition. By summing the total number of individuals in each of these nine categories, we obtain an expression for the total measured flow:

$$
\begin{aligned}
F_{E U}= & q_{E E} q_{E U} F_{E E}^{*}+q_{E E} q_{U U} F_{E U}^{*}+q_{E E} q_{N U} F_{E N}^{*} \\
& +q_{U E} q_{E U} F_{U E}^{*}+q_{U E} q_{U U} F_{U U}^{*}+q_{U E} q_{N U} F_{U N}^{*} \\
& +q_{N E} q_{E U} F_{N E}^{*}+q_{N E} q_{U U} F_{N U}^{*}+q_{N E} q_{N U} F_{N N}^{*} .
\end{aligned}
$$

Notice that regardless of his true labor market status, every individual has some chance of being recorded as making an $E+U$ transition. of course, for some individuals this probability is trivial. The number of individuals who in fact made $U \rightarrow E$ transitions but were twice misclassified, first as employed (when they were unemployed) and then as unemployed (when they were employed), and were therefore recorded as making $U \rightarrow E$ transitions, is likely to be quite small. The main contribution to the sum in (6) will come from the terms involving diagonal elements of the $Q$ matrix.

Equation (6) may be written more generally as 
(7)

$$
F_{k l}=\sum_{i} \sum_{j} q_{i k} q_{j l} F_{i j}^{*}
$$

We define $F$ to be the $3 \times 3$ matrix of observed flows:

(8)

$$
F=\left[\begin{array}{lll}
F_{E E} & F_{E U} & F_{E N} \\
F_{U E} & F_{E U} & E_{E N} \\
F_{N E} & F_{N U} & F_{N N}
\end{array}\right] .
$$

The system of nine equations like (7) can be compactly written as the matrix equation

$$
F=Q^{\prime} F * Q
$$

where $Q$ is the matrix of classification error probabilities $\left[\mathrm{q}_{i j}\right\}$ and $\mathrm{F}^{*}$ is the matrix of true flows. This equation expresses the observed flows as a function of the unobserved true flows and the classification error probabilities. It can be solved for the true flows:

$$
F^{*}=\left(Q^{-1}\right) \cdot F Q^{-1}
$$

Using our estimates of $\left\{q_{i j}\right\}$ to form $\hat{Q}$, we can estimate the true flows as

$$
\hat{F}^{*}=\left(\hat{Q}^{-1}\right) \cdot \hat{F Q}^{-1}
$$

This procedure can be applied to both aggregate gross flows and data for specific demographic groups, yielding a set of response-error corrected gross flows.

Associated with each matrix of the labor market flows, there is a matrix of transition probabilities. Define 
(12)

$$
P_{i j}=\operatorname{Pr}(\text { status in month } t+1=j \mid \text { status in month } t=1) \text {. }
$$

These probabilities can be estimated from the flows as:

$$
\hat{P}_{i j}=\frac{F_{i j}}{\sum_{k} F_{i k}} .
$$

Our calculations below present adjusted and unadjusted flows, as well as tran sition probabilities, for each demographic group.

An illustration of our adjustment procedure using total labor ret lows is shown in Table III. The table's first panel reports the annual average unadjusted flows for the period January 1977 to December 1982. Transition probabilities are shown beneath each flow. The table's next panel, labelled "Adjusted Flows, without Raking," reports the corrected gross flows calculated using the adjustment procedure described above. Some flows, particularly those involving tran* sitions into and out of the labor force, change dramatically. There is a deax reduction in the number of individuals who are of $f$ the diagonal of the flow matrix. While 12.602 million transitions are recorded in the actual gross flows data, our adjusted trix shows only 5.203 million transitions. This implies a reduction in the escape probabilities from each labor market state and a corresponding lengthening of the expected residence time in each state. A more complete discussion of the implications of these results for labor market dynamics is provided in the next section.

The procedure describe above does not impose any restictions on the number of individuals in each labor market state before and after the flow adjustment. Nor does it constrain the estinated fow dsta to be consistent with observed 
Table III: Total Labor Market Gross Flows with and without Adjustment

\begin{tabular}{lccc}
\hline \multirow{2}{*}{$\begin{array}{l}\text { Initial } \\
\text { State }\end{array}$} & \multicolumn{2}{c}{ Unadjusted Flows (Probabilities) } \\
\cline { 2 - 4 } Employed & Employed & Unemployed & NILF \\
\hline \multirow{2}{*}{ Unemployed } & 91,865 & 1,652 & 3,157 \\
& $(.950)$ & $(.017)$ & $(.033)$ \\
NILF & 1,857 & 3,899 & 1,521 \\
& $(.255)$ & $(.536)$ & $(.209)$ \\
& 2,805 & 1,610 & 55,541 \\
& $(.047)$ & $(.027)$ & $(.926)$ \\
\hline
\end{tabular}

\begin{tabular}{lccc}
\hline \multirow{2}{*}{$\begin{array}{l}\text { Initial } \\
\text { State }\end{array}$} & \multicolumn{3}{c}{ Adjusted Flows, Without Raking } \\
\hline \multirow{2}{*}{$\begin{array}{l}\text { Employed } \\
\text { Employed }\end{array}$} & 96,033 & Unemployed & NILF \\
Unemployed & $(.981)$ & 1,153 & 738 \\
& 1,405 & $(.012)$ & $(.008)$ \\
NILF & $(.187)$ & 5,392 & 724 \\
& $(.006)$ & $(.717)$ & $(.096)$ \\
& & $(.014)$ & 57,286 \\
& & & $(.980)$ \\
\hline
\end{tabular}

\begin{tabular}{lccc}
\hline \multirow{2}{*}{$\begin{array}{l}\text { Initial } \\
\text { State }\end{array}$} & \multicolumn{3}{c}{ Adjusted Flows, Raked } \\
\cline { 2 - 4 } Employed & Employed & Unemployed & NILF \\
\hline \multirow{2}{*}{ Unemployed } & 94,367 & 1,145 & 663 \\
& $(.981)$ & $(.012)$ & $(.007)$ \\
NILF & 1,420 & 5,509 & 668 \\
& $(.187)$ & $(.725)$ & $(.088)$ \\
& $(.006)$ & $(.016)$ & 58,286 \\
& & & $(.978)$ \\
\hline
\end{tabular}

Source: Unadjusted flows obtained from unpublished BLS tabulations for 1977-1982. The reported flows represent averages of the annual flows for this period. Adjusted flows are based on authors' calculations using the procedures outlined in the text. 
changes in labor market stocks. The adjustment procedure substantially lowers the number of individuals classified as NILF and raises the number of unemployed: In the unadjusted data, there are 59.956.milion individuals aut of the labor force and 7.27 million unemployed. In the adjusted case, however, the number of individuals who are NILF declines to 58.460 million, while the number of unemployed rises to 7.53 million. There are increases in the number of employed individuals as well.

A technique for modifying our adjusted flows to yield the same marginal totals as those implied by labor market stock data is to apply the method of iterative proportional fitting, or "raking," to our adjusted flows. Bishop, Feinberg, and Holland [3] describe this technique, developed by Deming and Stephan [7], for achieving comparability between cell proportions in a contingency table generated from one data source, and marginal totals generated from another source. We modfied our adjusted flows using this technique to conform with the annual average labor market stocks reported by the Bureau of Labor Statistics.5

The results of raking our adjusted flows are reported in the third panel of Table III. The raking adjustments lead to substantial changes in some of the flows. For example, the estimated $E \rightarrow E$ flow declines by over one and one half million persons, while the $N+N$ flow rises by one million. The implications of the flow matrix for labor market dynamics depend mostly on the associated transition probabilities, however, and there the raking adjustments have only trivial effects. The largest change in a transition probability is that for $P_{U U}$, which rises from .717 to .725 . The other transition probabilities hardly change 
at all. This suggests that relative to the correction for response errors, margin-consistency adjustments are of limited importance.

One important caveat about our procedure should be noted. We have presented no evidence to support our assumption that all individuals have identical, serially uncorrelated probabilities of response error. If this were not the case, our procedure would overstate the required adjustment to the gross flows and could lead to negative adjusted flows. Our assumption is not testable without longitudinal reinterview data. 


\section{Results}

This section analyzes the results of applying our adjustment procedure to the gross changes data for the total population, teenagers, Men, Women, Men 16-19, Men 20-24, Men 25-59, Women 16-19, Women 20-24, and Women 25-59. In each case the values of $\left\{q_{i j}\right\}$ are estimated from Reinterview Survey data for the period January through June 1981 , and are used to adjust the annual average gross changes for the period 1977-1982. This section draws only on adjusted flows which have been raked for consistency with the labor market stocks. Unadjusted, adjusted but unraked, as well as adjusted and raked flows with their associated transition probabilities are reported in the Appendix.

The comparison of adjusted and unadjusted flows is of some interest in itself. In addition, however, labor market dynamics can be analyzed by reference to several other statistics which can be derived from the transition probability matrices. These include the expected duration of a completed spell in each labor force state, the probability of an unemployment spell ending in employment, and the probability of labor force withdrawal within a given month. Expected durations of completed spells in each state are calculated as the reciprocal of the exit probability from that state. As discussed in more detail below, the expected duration of a completed spell of unemployment differs from the mean duration of interrupted spells published each month by the Bureau of Labor Statistics. Our calculation depends only on a simple identity linking flows and stocks, and not on any assumption about the Markovian character of actual labor market behavior. The probability of an unemployment spell ending in employment entry is calculated as the ratio $P_{U E} /\left(P_{U E}+P_{U N}\right)$, while the probability of labor force withdrawal is calculated as $\left(P_{U N} \pi_{U}+P_{E V} I_{E}\right) /\left(I_{E}+\pi_{U}\right)$. 
$\Pi_{U}$ and $\pi_{E}$ denote, respectively, the steady state fraction of the population unemployed and employed.

Marston [16] has presented a very complete analysis of the transition matrix differences between demographic groups. Two central conclusions of his analysis were the importance of transitions into and out of the labor force, and the great extent of turnover in the labor market. Here we focus on the extent to which these conclusions are modified when we make use of our adjusted data. We then examine the implications of our findings for analyses such as those of Kaitz [14] and Lancaster [15] which explore labor market dynamics without making explicit reference to gross changes data.

Table IV presents estimates of the monthly probability of labor market withdrawal, for different demographic groups, estimated from our unadjusted and adjusted data. A striking feature of the unadjusted data is the apparently overwhelming importance of labor force withdrawal. The unadjusted data imply that over forty percent of the whole labor force can be expected to leave the labor force within a year. For women, the comparable statistic approaches fifty-five percent. The unadjusted data also show that among job leavers, labor force withdrawal is almost twice as common as unemployment. This calculation is based on the ratio of $P_{E N} /\left(P_{E N}+P_{E U}\right)$, using data reported in the appendix. Perhaps most significant, the unadjusted data imply that almost half ( 45 percent) of unemployment spells end in labor force withdrawal. Table $V$ reports values of one minus this probability, the chance that conditional upon escaping from unemployment the individual finds a job. For women, forty-six percent of unemployment spells end in successful job- 
Table IV: Probability of Labor Force Withdrawal

Demographic
Group

Total

Total 16-19

Men

Men 16-19

Men 20-24

Men 25-59

Women

Women 16-19

Women $20-24$

Women 25-59
Probability of Labor Force Withdrawal

Unadjusted Flows Adjusted Flows Percentage Change

.045

.013

$-71.1 \%$

.146

.070

$-52.1 \%$

.030

.006

$-80.0 \%$

.139

.094

$-32.4 \%$

.042

.016

$-61.9 \%$

.011

.001

$-90.9 \%$

.065

.022

$-66.2 \%$

.154

.098

$-36.4 \%$

.070

.031

$-55.7 \%$

.050

$-68.0 \%$

Source: The probability of labor force withdrawal is defined as $\left(P_{E N} I_{E}+\right.$ $P$. $\left.\Pi_{1}\right) /\left(\pi_{1}+\pi_{1}\right)$. Calculations reported here are based ON Ennual aterage flows for 1977-1982 provided by the Bureau of the Census. Error-adjustment algorithm is described in the text. 
finding; for men aged $25-59$, the probability is .75 .

As already emphasized, the Reinterview Survey information suggests that spurious reporting of labor force withdrawal is the most common form of reporting error. Hence, it is not surprising that the adjusted data present a very different view of the importance of labor force withdrawal. The overall withdrawal rate is only about one-third as great for the entire population, as is suggested by the unadjusted data. In contrast to the unadjusted data, job leaving to unemployment is twice as common as job leaving followed by labor force withdrawal. The adjusted data also imply that about two-thirds of the unemployed end their spell of unemployment by finding a job.

The differences between the unadjusted and adjusted probabilities vary across demographic groups. The largest proportionate changes in withdrawal probabilities are for those groups with the lowest initial withdrawal rates. For mature men, for example, there is a ninety percent reduction in withdrawal probabilities. Male teenagers, who exhibit high mobility, experience only a thirty percent reduction as a result of flow adjustment. The probability of a successful escape from unemployment rises for nearly all demographic groups. These changes are most pronounced for men aged 25-59.

A second striking feature of the unadjusted data is the apparently very high rate of turnover in the labor force. This is illustrated in Table VI, which provides estimates of unemployment durations using adjusted and unadjusted flows data. For the entire population the unadjusted data suggest that the mean duration of unemployment is only about 2.2 months. For women the estimated durations are shorter, and for teenagers, they are far shorter, 1.8 months. The 
Table V: Probability of Successful Unemployment Escape

Demographic Group

\section{Total}

Total 16-19

Men

Men 16-19

Men 20-24

Men 25-59

Women

Women 16-19

Women $20-24$

Women 25-59
Probability of Successful Escape from Unemployment Unadjusted Flows Percentage Change

$$
.550
$$

.642

.481

.693

.749

.461

.428

.517

.465
.680

.597

.796

.467

.928

$* * * *$

.594

.497

.546

.665
$28.9 \%$

$16.1 \%$

$5.6 \%$

\section{$23.6 \%$}

$31.2 \%$

$24.0 \%$

$-2.9 \%$

$33.9 \%$

$* * * *$

$43.0 \%$

Source: The probability of successful unemployment escape is defined as $\mathrm{P}_{\mathrm{H}} /\left(\mathrm{P}_{\mathrm{HE}}+\mathrm{P}_{\mathrm{HN}}\right)$. Results reported here were calculated from annual a Erage flows for 1977-1982 provided by the Bureau of the Census. Error-adjustment algorithm is described in the text. For Men 25-59, the probability of successful escape from the adjusted data was negative. 


$$
-24-
$$

Table VI: Expected Unemployment Durations

Demographic Group
Expected Unemployment Duration(months)

Unadjusted Flows $\quad$ Adjusted Flows Percentage Change

3.64

$69.3 \%$

Total

Total 16-19

1.78

2.26

$27.0 \%$

Men

2.39

4.49

$87.9 \%$

Men 16-19

1.83

2.56

$39.9 \%$

Men 20-24

2.39

5.39

$25.5 \%$

Men 25-59

2.16

4.70

$17.6 \%$

Women

1.97

3.10

$57.4 \%$

Women 16-19

1.73

2.27

$31.2 \%$

Women 20-24

2.02

2.96

$46.5 \%$

Women 25-59

2.08

3.76

$80.8 \%$

Source: Expected unemployment durations were calculated as $1 / P^{*}$ Results reported here were based on annual average flows for $1997-1982$ provided by the Bureau of the Census. Error-adjustment algorithm is described in the text. 
adjusted data tell a rather different story. For the entire population the estimated duration of a completed unemployment spell is 3.64 months, almost twothirds greater. For women, the expected spell duration rises from 2.0 to 3.1 months, while for men the change is even more pronounced, 2.4 to 4.5 months. Our adjustments accentuate the differences between teenagers and the remainder of the population, because they revise upwards the teenagers' durations of unemployment by only small amounts.

It is interesting to note that our adjustments have their most dramatic effects on groups whose labor market behavior is least dynamic. If error rates are relatively constant across demographic groups, then ellminating errors will have the greatest proportional effect on groups whose members make the fewest transitions. The point is exemplified by considering the men 25-59 group. Here the estimated duration of unemployment more than doubles from 2.16 months to 4.70 months. Unfortunately, these results must be discounted because some of the adjusted flow probabilities are negative. This is probably a consequence of positive serial correlation in reporting errors and suggests that all our estimates may somewhat overstate the appropriate adjustments. It also suggests the importance of demographic disaggregation in adjusting these data. This pitfall would not be visible had we worked only with data on men and women as done by Abowd and Zellner $[1]$ and Fuller and Chua [10].

It seems inevitable that correction for reporting errors which lead to overestimates of close to seventy percent in the escape rate from unemployment are likely to dramatically increase reasonable estimates of any unemployment duration measure. It follows naturally that even estimates such as those of 
Clark and Summers [6] are likely to underestimate the true extent of concentration in unemployment.

There is some support for our suggestion that unemployment spells are longer than usually shown in gross changes data. Non-CPS sources of labor market information, which are usually retrospective surveys of individual experience, often find spell lengths for all labor market states which are longer than those reported by the CPS.6 While interpretation of these facts is complicated by the varying definitions of unemployment used on non-CPS surveys, they corroborate our findings.

On balance, our results suggest that the unadjusted gross changes data lead to very misleading inferences about the character of the labor market. We suspect that similar problems plague efforts to use the gross changes data to study cyclical phenomena. In particular, conventional analyses ma understate the cyclicality of labor market flows because a relatively constant number of spurious flows are added in all periods to the cyclically variable true flows.

We believe that our results also cast doubt on conventional analyses of unemployment which do not make explicit use of the gross changes data. One common method for analyzing unemployment durations, pioneered by Kaitz [14] and Salant [20], involves inferring the distribution of completed spell lengths from published information on the distribution of interrupted spell lengths. A simple procedure of this type is to estimate the mean duration of completed spell lengths by dividing the number of unemployed persons by an estimate of the flow rate into unemployment, based for example on the number of persons unemployed less than 5 weeks. For 1981 this procedure yields a mean 
duration of completed unemployment spells of 2.39 months, very close to the estimate produced by the unadjusted gross changes data. The reason for this should be clear. A large number of persons are spuriously classified as unemployed, artificially inflating the stock of short term unemployed. Likewise, many of the longer term unemployed are spuriously not measured as unemployed. These biases imply that these published data also understate the mean duration of incomplete spells of unemployment.

Related difficulties plague studies of the transition out of unemployment which use the techniques of survival analysis, such as Lancaster [15]. Some transitions out of unemployment are spurious, and some spells of unemployment are recorded as ending when they are in fact continuing. Estimated hazard functions correspond not to the probability of escaping unemployment, but to the probability of being measured as leaving unemployment. The latter may be the outcome of either a classification error or a genuine labor market transition; this complicates the structural interpretation of hazard models.

Still further difficulties infect procedures which rely upon individuals' reported unemployment "durations, since these data are often extremely unreliable. One way to illustrate this is by comparing the reported unemployment durations of Current Population Survey respondents who are unemployed in two consecutive months. The surveys occur roughly four weeks apart, so for individuals experiencing a continuing unemployment spell the duration reported in month two should exceed that in month one by between three and five weeks. Table VII reports the results of a tabulation of unemployment duration differences for a sample of CPS respondents from May, 1976. Less than one third 
Table VII: Errors in Reported Durations of Unemployment

Month-to-Month Difference in Reported Spell Duration

Negat1ve

0 weeks

1-2 weeks

3-5 weeks

6-9 weeks

10-15 weeks

16-24 weeks

$25+$ weeks
All Workers

$14.26 \%$

$7.41 \%$

$9.86 \%$

$31.78 \%$

$15.97 \%$

$7.74 \%$

$4.65 \%$

$8.31 \%$

\begin{tabular}{c} 
Workers with \\
DUR $<20$ \\
\hline
\end{tabular}

$25.55 \%$

$12.34 \%$

$7.48 \%$

$24.67 \%$

$11.68 \%$

$7.71 \%$

$3.53 \%$

$7.05 \%$
Workers with DUR $>20$

$7.63 \%$

$4.52 \%$

$11.25 \%$

$35.96 \%$

$18.50 \%$

$7.76 \%$

$5.30 \%$

$9.06 \%$

Source: Calculations based on May 1976 CPS questionnaire participants who were classified as unemployed in both May and June, who were more than sixteen years of age, and who reported June unemployment durations of more than 4 weeks. DUR is the reported unemployment duration in May, 1976. See Poterba and Summers (1984) for further details. 
of the individuals surveyed provided consistent responses in the two months, and more than twenty percent reported shorter durations, or the same duration, on the second survey. Moreover, there is a substantial incidence of large changes, more than four months, in the reported durations in the two surveys. These findings suggest that any attempt to apply techniques which are not robust against measurement errors to analyze duration-related phenomena such as job-finding are prone to yield substantially misleading results.

A full analysis of how response errors affect the measured duration of unemployment spells would require a statistical model of how spuriously misclassified individuals report durations, both during and after their response error. We have previously [18] presented some fragments of evidence on this question. We showed that of those who are classified as unemployed, NILF, and unemployed in three successive months, less than one third report an unemployment duration which increases by more than two months between the two periods of unemployment. On the other hand, less than a quarter consider themselves as beginning a new spell and report durations of less than one month during the second spell of unemployment. These results suggest the difficulties with any simple assumption about how classification errors affect reported durations. 


\section{Conclusions}

This paper has developed a procedure for adjusting the Current Population Survey gross changes data for reporting errors. The corrected data suggest that the labor market is much less dynamic than has frequently been suggested. Conventional measures may understate the duration of unemployment by as much as eighty percent and overstate the extent of movement into and out of the labor force by several hundred percent. The use of our adjusted data also throw demographic differences in patterns of labor market dynamics into much sharper relief.

This research could usefully be extended in several directions. A number of methodological issues should be explored. Alternative procedures for estimating CPS error rates could be devised to relax the assumption that the reconciliation process correctly estimates individuals' true labor force status. Error probabilities could also be estimated imposing the constraint that the marginal labor market stocks estimated in the CPS are unbiased estimates of the true stocks. Allowance could be made for heterogeneity within demographic groups in the likelihood of reporting errors. Alternative procedures to adjust the actual gross changes data could also be developed.

It would also be valuable to adjust data for several years, to allow study of cyclical aspects of labor market dynamics. Explorations of the importance of reporting errors for studies of inter-industry or occupational flows would also be valuable. It would be particuarly useful to examine the incidence of reporting errors as a function of an individual's duration in a state so as to evaluate the reliability of conclusions reached by applying hazard function 
methodologies to labor market data. Another important area for further research is the effect of reporting errors in retrospective surveys such as the National Longitudinal Survey •

Our findings suggest that measurement errors importantly distort estimates of even basic statistics characterizing the labor market. Statistical techniques for analyzing labor market data which take account of pervasive measurement errors need to be developed. Because of the discrete nature of the data, and its longitudinal character, standard techniques for the treatment of errors in variables are not applicable. In work now underway [19], we are developing a multinomial logit procedure for analyzing labor market transitions which are reported with error. 


\section{Footnotes}

1. Recent studies including Clark and Summers [5], Smith and Vanski [23], and Smith [22], have used unpublished gross flows data to examine labor market dynamics.

2. The CPS Reinterview Survey is described in some detail in Census Technical Report \#19 [4], Woltman and Schreiner [25], and Graham [11].

3. An alternative procedure which constrains the estimated $\left\{q_{f f}\right\}$ to leave the labor market stocks invariant is reported in Fuller and Chua $\$ 9,10\}$.

4. Discussion of the bias induced by the reconciliation procedure may be found in Schreiner [21].

5. Data on annual labor market stocks were obtained from the January issues of Employment and Earnings.

6. Clark and Summers [6] discuss some of this evidence. 


\section{REFERENCES}

1. Abowd, J., and A. Zellner: "Estimating Gross Labor Force Flows." Mimeographed, Graduate School of Business, University of Chicago, 1984.

2. Akerlof, G. and B. Main: "Unemployment Spells and Unemployment Experience," American Economic Review 70 (1980), 885-93.

3. Bishop, Yvonne M., Stephen E. Feinberg, and Paul Holland: Discrete Multivariate Analysis: Theory and Practice Cambridge, MIT Press, 1975.

4. Bureau of the Census: The Current Population Survey Reinterview Program: January 1961 through December 1966: Technical Paper No. 19. Washington, D.C.: Government Printing Office, 1969.

5. Clark, K. B. and L.H. Summers: "Labor Market Dynamics and Unemployment: A Reconsideration," Brookings Papers on Economic Activity, 1979, 13-60.

6. $\quad$ : "Labor Force Transitions and Unemployment," Working Paper Number 277, National Bureau of Economic Research, Cambridge, Mass., 1978.

7. Deming, W.E. and F.F. Stephan: "On a Least Squares Adjustment of a Sampled Frequency Table when the Expected Marginal Totals are Known," Annals of Mathematical Statistics 11 (1940), 427-44.

8. Feldstein, M.S.: Lowering the Permanent Rate of Unemployment. Washington: Government Printing office, 1973.

9. Fuller, W.A. and T.C. Chua: "A Model of Multinomial Response Error," U.S. Bureau of the Census, April 1983.

10. Response Error," paper prepared for Bureau of Labor Statistics/Bureau of the Census Conference on Gross Change Estimation, July 1984.

11. Graham, D.W.: "Estimation, Interpretation, and Use of Response Error Measurements. Mimeographed, U.S. Department of Commerce, Washington, D.C., 1979 .

12. Hall, R.E.: "Turnover in the Labor Force," Brookings Papers on Economic Activity $(1972): 3$.

13. Hall, R.E.: "A Theory of the Natural Unemployment Rate and the Duration of Unemployment," Journal of Monetary Economics 5 (1979), 153-69.

14. Kaitz, H.B.: "Analyzing the Length of Spells of Unemployments" Monthly Labor Review 93 (November 1970), 11-20.

15. Lancaster, T.: "Econometric Methods for the Duration of Unemployment," Econometrica 47 (1979), 939-56. 
16. Marston, S.I.: "Employment Instability and High Unemployment Rates," Brookings Papers on Economic Activity 1: 1976.

17. National Commission on Employment and Unemployment: Counting the Labor

Force. Washington, Government Printing Office, 1979.

18. Poterba, J.M., and L.H. Summers: "Survey Response Variation in the Current Population Survey," Monthly Labor Review (March 1984), 31-37.

19. : "Multinomial Logit with Errors in Classifications." Mimeo, Massachusetts Institute of Technology, Cambridge, Mass., 1982.

20. Salant, S.W.: "Search Theory and Duration Data: A Theory of Sorts," Quarterly Journal of Economics 91 (1977), 39-57.

21. Schreiner, I.: "Reinterview Results from the CPS Independent Reconcilation Experiment." Unpublished manuscript, Bureau of the Census, Washington, D.C., 1980

22. Smith, R.E.: "Dynamic Determinants of Labor Force Participation: Some Evidence from Gross Change Data," Working Paper 350-49, Washington, D.C., The Urban Institute, 1973.

23. Smith, R.E., and J. Vanski: The Volatility of the Teenage Labor Market: Labor Force Entry, Exit, and Unemployment Flows," paper prepared for presentation to the Conference on Employment Statistics and Youth sponsored by the U.S. Department of Labor, February 11, 1979.

24. : "Gross Change Data: The Neglected Data Base," in National Commission on Employment and Unemployment, Appendix Volume II Washington: Government Printing Office, 1979.

25. Woltman, Henry and Irv Shreiner: "Possible Effects of Response Variance on the Gross Changes Data." Unpublished Bureau of Census memo, Washington, D.C., May 11, 1979. 


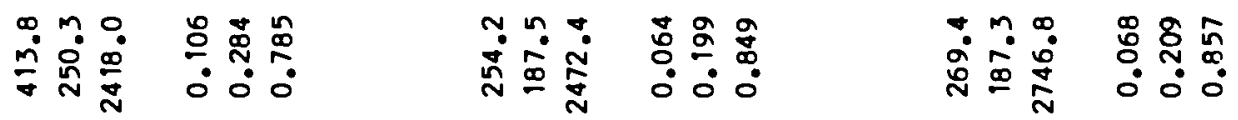

\begin{tabular}{|c|c|}
\hline 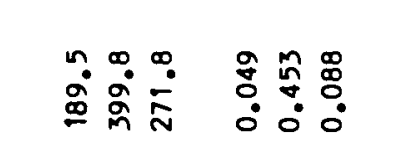 & 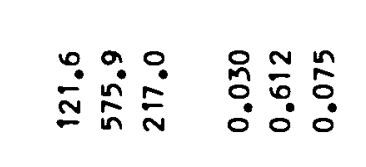 \\
\hline 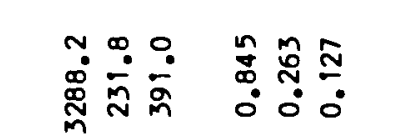 & 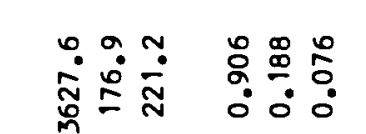 \\
\hline
\end{tabular}

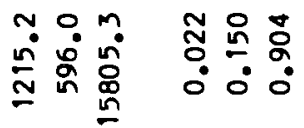

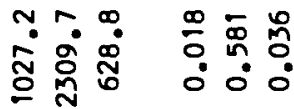

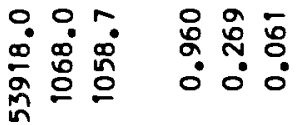

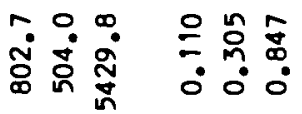

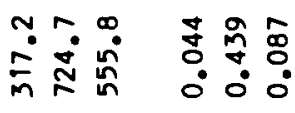

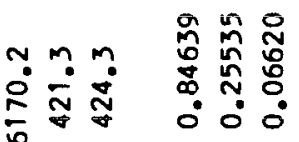

ำ

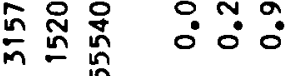

喜

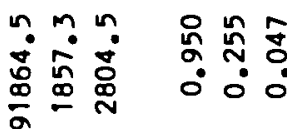

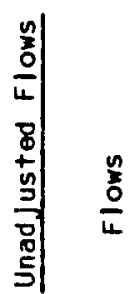

$\frac{1}{ \pm}$
$\frac{1}{2}$
$\frac{0}{8}$
$\frac{1}{2}$

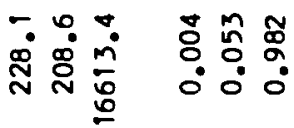

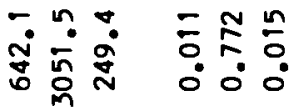

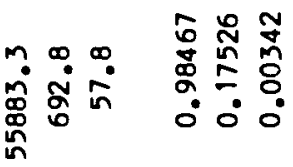

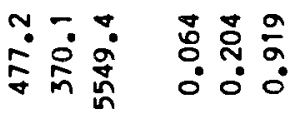

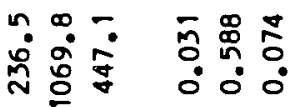

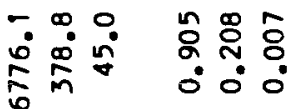

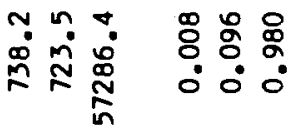

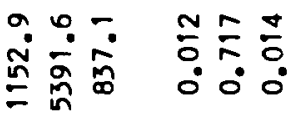

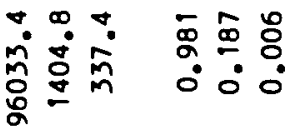

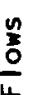

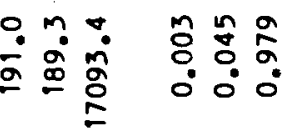

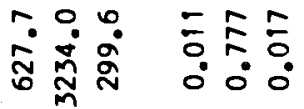

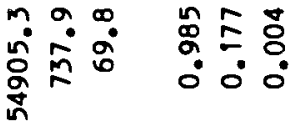

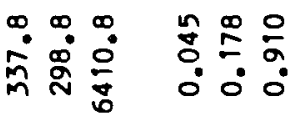

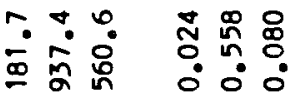

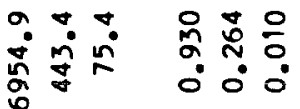

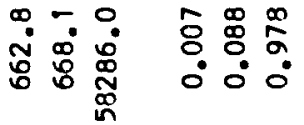

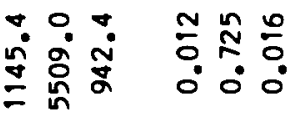

$\because \sim \curvearrowleft$ Ф

m 


\begin{tabular}{|c|c|c|c|c|c|}
\hline$\stackrel{\infty}{\infty} \stackrel{\infty}{\infty}$ & 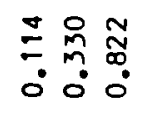 & 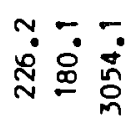 & 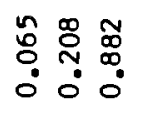 & m. & 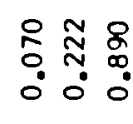 \\
\hline 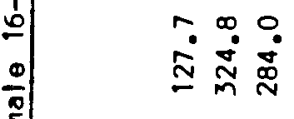 & 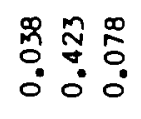 & 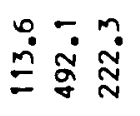 & 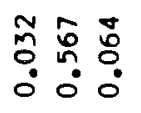 & 它落 & $\begin{array}{l}\text { m. } 0.8 \\
0 \\
0 \\
0\end{array}$ \\
\hline 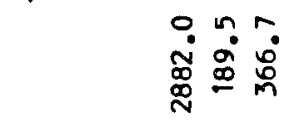 & 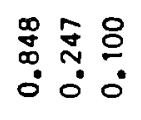 & 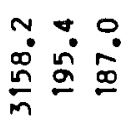 & 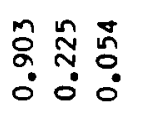 & ஜே் & 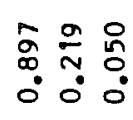 \\
\hline
\end{tabular}

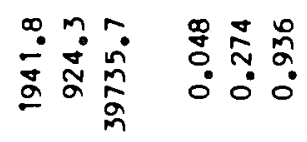

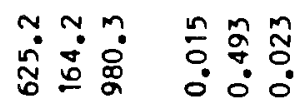

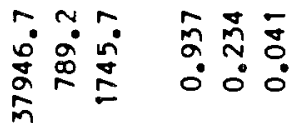

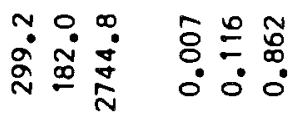

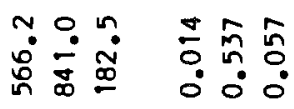

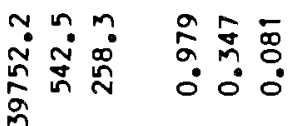

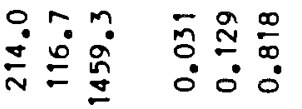

ஸे
$\vdots$
$\frac{1}{2}$
$\frac{0}{2}$

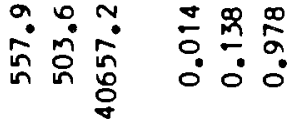

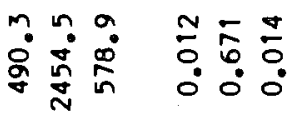

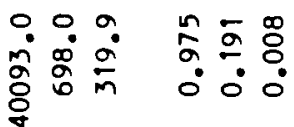

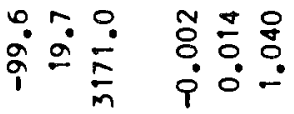

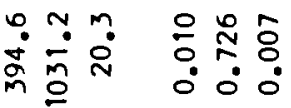

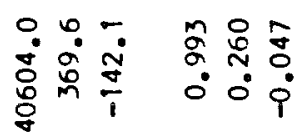

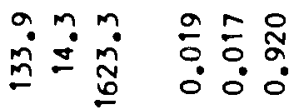

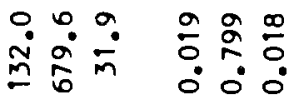

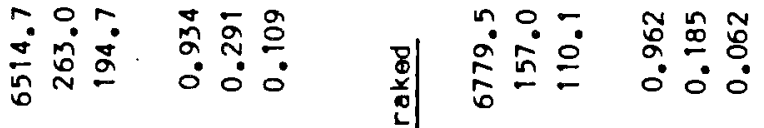

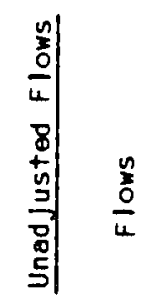

$\frac{8}{E}$
\pm
0
0
0
0

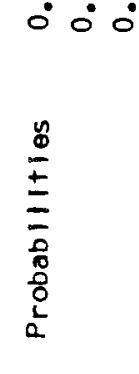

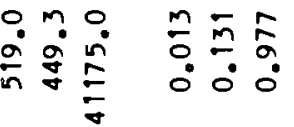

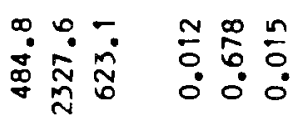

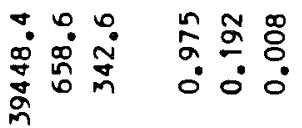

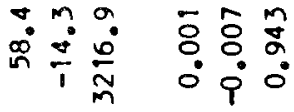

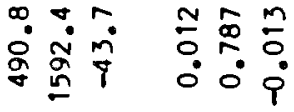

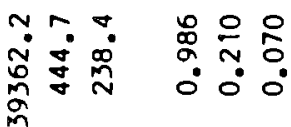

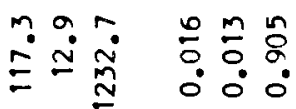

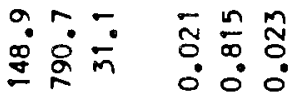

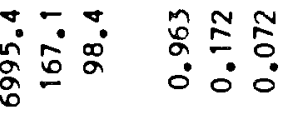



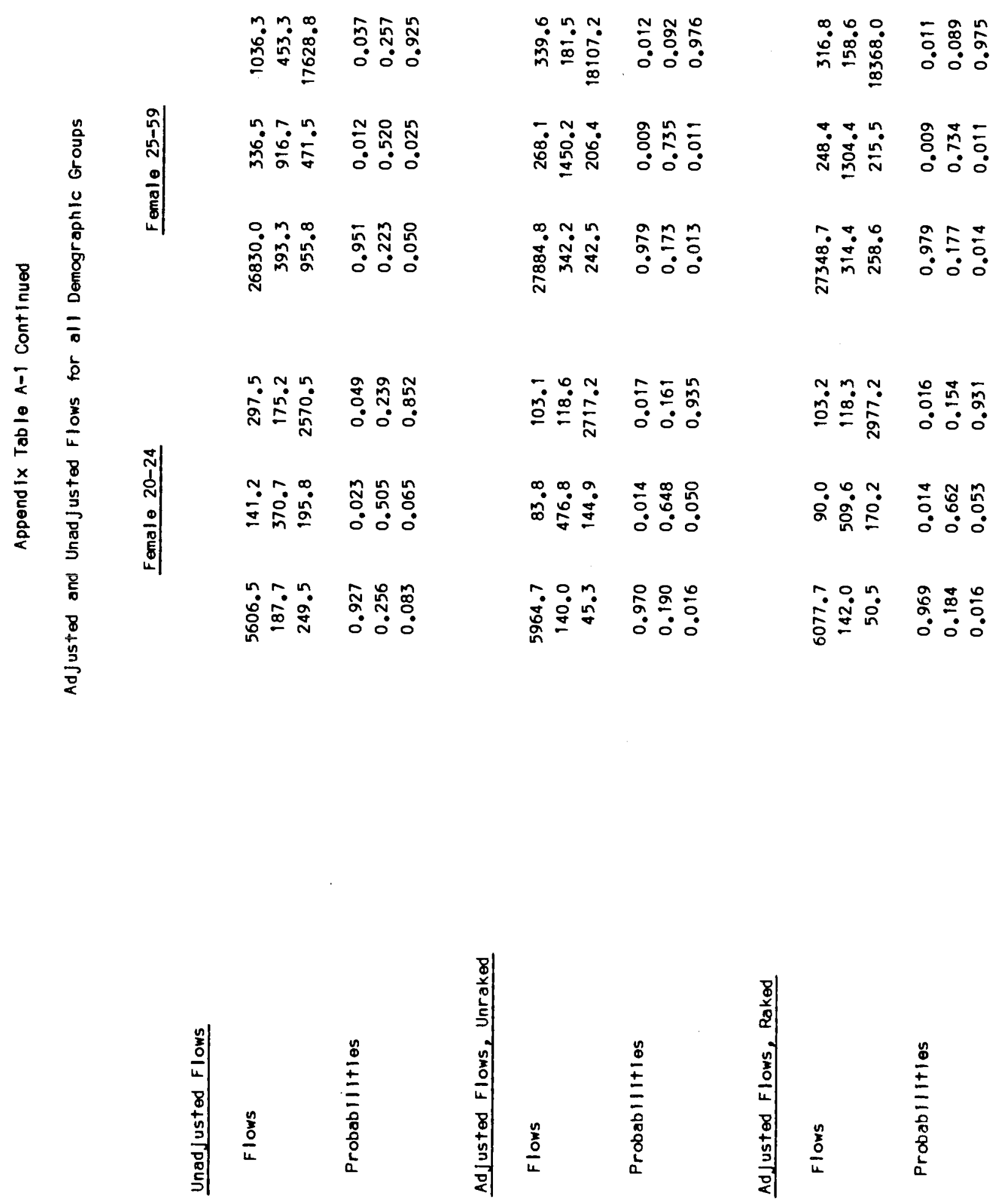